\title{
What To Do When Fires Fuel Weeds A step-by-step guide for managing invasive plants after a wildfire.
}

\author{
By Kim M. Goodwin and Roger L. Sheley
}

$\mathrm{T}$ he ecological effects of wildfires are typically beneficial given the natural role of fire in perpetuating ecosystems. Fires remove dead and built-up vegetation that hinders new growth and quickly releases nutrients bound up in litter, enriching the soil. Depending on fire severity and plant characteristics, many plants will survive and reinitiate growth soon after a fire.

However, the ability of survived plants to reestablish, thrive, and reseed in subsequent years will be greatly affected by the presence of invasive plants. These non-indigenous, highly competitive and aggressive plants invade and displace native plant communities. Burned area invasive plant presence can occur as a result of improper preventative management or survival of invasive plants existing prior to the fire.

Burned areas can contain high nutrient levels, exposed ground surfaces, and low shade with high light conditions. These disturbances directly favor colonization of new and survived invasive plants. Survival coupled with disturbances produced by fire can cause rapid and expanded invasive plant growth.

As a result, values such as wildlife habitat, livestock forage production, watershed stability, and water quality often deteriorate. If permitted to reach large infestation levels, the invasive plants will persist and be difficult and expensive to manage.

To prevent invasive plants from overtaking burned areas, all burned and adjacent areas should be managed using a burned area invasive plant management plan. When properly designed and implemented, an invasive

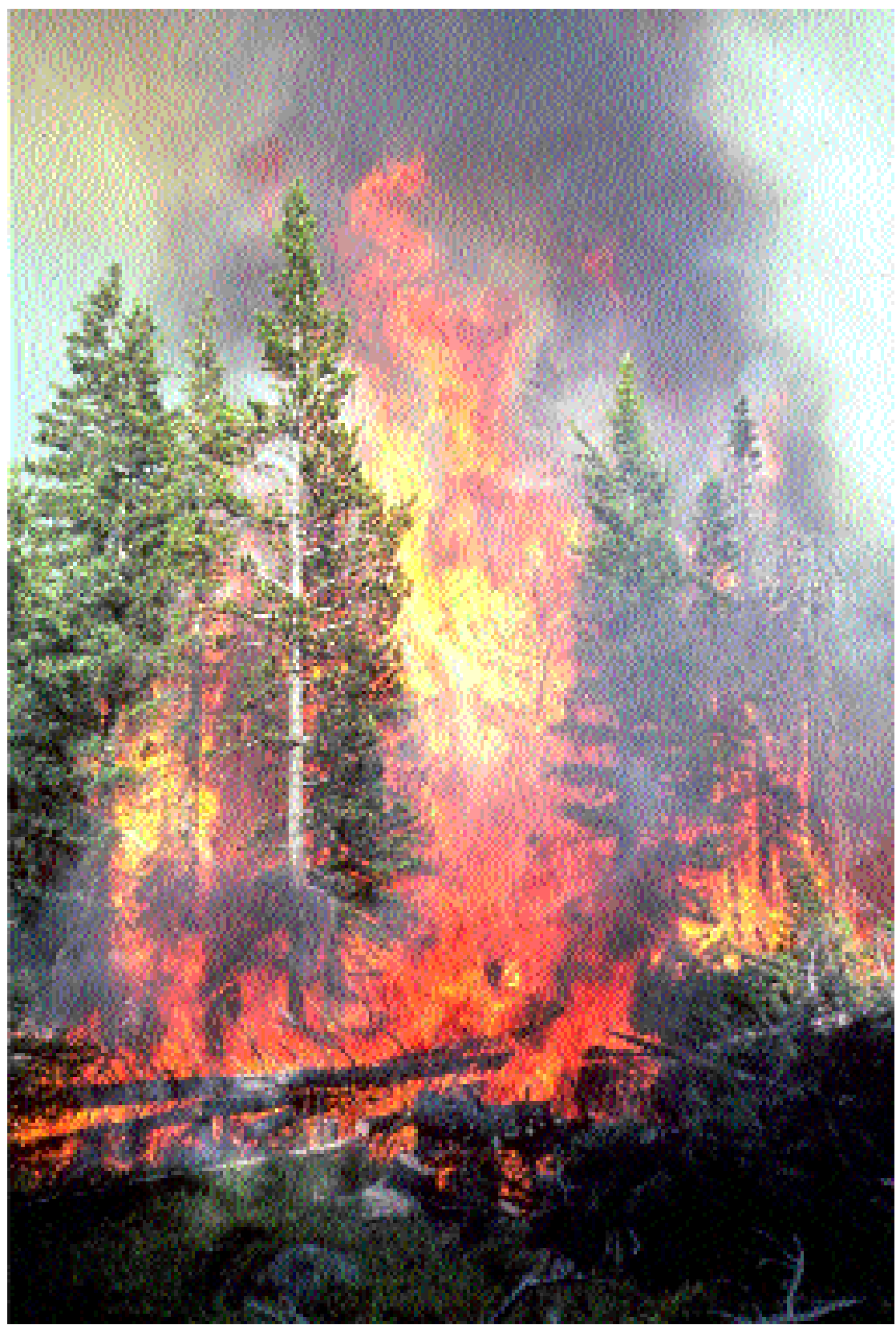

A high-intensity fire during the Yellowstone NP, U.S.A. fires of 1988. Photo courtesy of the Bureau of Land Management. 
plant management plan should:

- Prevent the establishment and growth of invasive plants into weed-free burned areas and adjacent unburned areas

- Mitigate the reestablishment of invasive plants in burned areas

- Establish and maintain healthy, weed-resistant plant communities (few resources are available to a potential invader) that meet other land use objectives.

\section{Step 1. Natural Recovery Potential}

Directly following a fire, managers should determine the necessity of implementing revegetation efforts. Estimating the natural recovery potential of the burned area, or the capability of the burned area to recover naturally without revegetation, can accomplish this. Revegetation necessity can be based on desired vegetation survival as a result of burn severity (Table
1) and the degree of desired vegetation displaced by invasive plants prior to burning. Revegetation necessity can also be related to invasive plant survival as viable seeds, root crowns, or rhizomes capable of reproduction.

Burn intensity is a function of fire temperature and duration, largely determined by wind speed and the moisture content and amount of fuel present during a fire. Burn severity is a function of the amount of moisture in the organic soil layer during a fire. A high intensity/low severity burn can occur when fuels are dry but the litter/duff layer is wet. Although such a fire exhibits a high intensity burn, very little subsurface heating can occur as a result of the wet organic layer that, in turn, can yield high desired plant survival and rapid natural recovery. A high burn intensity/high severity burn can occur as above, but with a dry litter/duff layer. As a result, much subsurface heating can occur, yielding low desired plant survival and slow natural recovery.

Invasive plant survival through viable seeds varies among species depth of burial, and burn severity. Most invasive rhizomatous plants (Canada thistle, Dalmatian toadflax, leafy spurge, Russian knapweed, whitetop, etc.) have high survival regardless of burn severity given that even the most severe fires typically damage roots only to four inches below the soil. Many rhizomatous weeds have roots that penetrate the soil far below this depth. For instance, roots of leafy spurge can extend to depths of 26 feet, with vegetative root buds at depths of ten feet or more (Lajeunesse et al. 1999). Revegetation, when necessary (Table 2 ), can provide competitive plants that restore and maintain landscape stability and productivity, while reducing weed invasion and/or reestablishment plants. Revegetation should be considered when anticipated desired vegetation cover is inadequate; typically, less

Table 1. Determining burn severity (adapted from "Fire Burn Severity" [unpublished], Gallatin National Forest, Montana)

\begin{tabular}{|c|c|c|c|}
\hline Burned area characteristics & Low-severity & Medium-severity & High-severity \\
\hline Soil color and condition & $\begin{array}{l}\text { Normal color; soil is not } \\
\text { physically affected }\end{array}$ & $\begin{array}{l}\text { Up to two inches of soil } \\
\text { darkened brown to } \\
\text { reddish-brown below the duff } \\
\text { or ash layer; soil is not } \\
\text { physically affected }\end{array}$ & $\begin{array}{l}\text { Two to four inches of soil is } \\
\text { dark ened reddish-orange; } \\
\text { soil can be physically affected: } \\
\text { crusted, crystallized, } \\
\text { and/or agglomerated }\end{array}$ \\
\hline Duff and debris & Duff and debris partly burned & $\begin{array}{l}\text { Duff consumed; burned debris } \\
\text { (e.g. needles) still evident }\end{array}$ & $\begin{array}{l}\text { Duff and debris entirely } \\
\text { consumed }\end{array}$ \\
\hline Ash characteristics & Generally dark colored & Dark colored ash present & $\begin{array}{l}\text { Uniformly gray/white ash } \\
\text { present; in severe cases, ash } \\
\text { is white and light }\end{array}$ \\
\hline Hydrophobicity* & $\begin{array}{l}\text { Low to absent; water } \\
\text { infiltration not significantly } \\
\text { changed }\end{array}$ & $\begin{array}{l}\text { Low to medium on } \\
\text { surface soil and up to one } \\
\text { inch deep }\end{array}$ & $\begin{array}{l}\text { Medium to high, } \\
\text { up to two inches deep }\end{array}$ \\
\hline $\begin{array}{l}\text { Shrub stump, small } \\
\text { fuels condition }\end{array}$ & Slightly charred & Charred but still present & Entirely absent \\
\hline Plant survival $\dagger$ & $\begin{array}{l}\text { High; root crowns and } \\
\text { surface roots will resprout } \\
\text { quickly }\end{array}$ & $\begin{array}{l}\text { Moderate; roots and rhizomes } \\
\text { below one inch will resprout }\end{array}$ & $\begin{array}{l}\text { Roots burned up to four inches } \\
\text { below surface; roots and } \\
\text { rhizomes deep in soil } \\
\text { can resprout }\end{array}$ \\
\hline Natural recovery potential & $\begin{array}{l}\text { Quick; natural recovery } \\
\text { within one to two years }\end{array}$ & $\begin{array}{l}\text { Modest; natural recovery in } \\
\text { two to five years }\end{array}$ & Slow; natural recovery limited \\
\hline
\end{tabular}

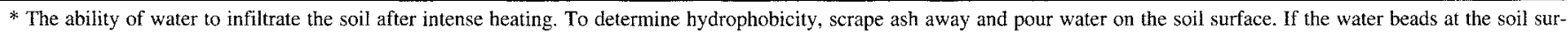
face, soil is hydrophobic. Test for hydrophobicity at several depths (up to four inches) as hot fires can drive hydrophobic layers several inches into the soil.

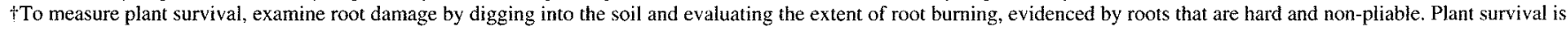
also a function of survived viable seeds in the soil.

$\ddagger$ Delayed recovery time likely with moderate to high noxious weed cover 
Table 2. Determining burned area revegetation necessity

\begin{tabular}{|c|c|c|c|}
\hline \multirow[t]{2}{*}{ Invasive plant } & \multicolumn{2}{|c|}{ Burn severity } & \multirow[b]{2}{*}{ High } \\
\hline & Low & Medium & \\
\hline $\begin{array}{l}\text { Absent to low - up to } 20 \% \\
\text { weed cover (i.e. rare to } \\
\text { regularly scattered) } \\
\text { High pre-burn cover of } \\
\text { desired vegetation }\end{array}$ & $\begin{array}{l}\text { Revegetation not necessary; } \\
\text { ecological effects generally } \\
\text { beneficial; regularly monitor for } \\
\text { new weeds until community reaches } \\
\text { recovery, then monitor occasionally }\end{array}$ & $\begin{array}{l}\text { Revegetation not necessary; } \\
\text { ecological effects generally beneficial; } \\
\text { regularly monitor for new weeds } \\
\text { until community reaches recovery, } \\
\text { then monitor occasionally }\end{array}$ & $\begin{array}{l}\text { Revegetation and regular } \\
\text { weed management } \\
\text { recommended }\end{array}$ \\
\hline $\begin{array}{l}\text { Moderate - between } 20 \text { and } 80 \% \\
80 \% \text { weed cover (i.e. frequent } \\
\text { to fairly dense) } \\
\text { Moderate pre-burn cover of } \\
\text { desired vegetation }\end{array}$ & $\begin{array}{l}\text { Revegetation may be necessary } \\
\text { if desired vegetation cover is below } 30 \% \text {; } \\
\text { frequent weed management recommended; } \\
\text { high survival of most weed species }\end{array}$ & $\begin{array}{l}\text { Revegetation may be necessary } \\
\text { if desired vegetation cover } \\
\text { is below } 30 \% \text {; frequent weed } \\
\text { management recommended; weed } \\
\text { survival varies between species* }\end{array}$ & $\begin{array}{l}\text { Revegetation and fre- } \\
\text { quent weed management } \\
\text { recommended; weed sur- } \\
\text { vival varies between } \\
\text { species* }\end{array}$ \\
\hline $\begin{array}{l}\text { High - between } 80 \text { and } 100 \% \\
\text { weed cover (i.e. dense } \\
\text { to monoculture) } \\
\text { Low to absent pre-burn cover } \\
\text { of desired vegetation }\end{array}$ & $\begin{array}{l}\text { Revegetation and intense weed } \\
\text { management recommended; } \\
\text { high survival of most weed species }\end{array}$ & $\begin{array}{l}\text { Revegetation and intense weed } \\
\text { management recommended; } \\
\text { weed survival varies between } \\
\text { species* }\end{array}$ & $\begin{array}{l}\text { Revegetation and } \\
\text { intense weed } \\
\text { management recommended; } \\
\text { weed survival varies } \\
\text { between species* }\end{array}$ \\
\hline
\end{tabular}

*Rhizomatous weeds have high survival as underground vegetative structures still capable of reproduction; weed survival as root crowns or viable seeds varies between species.

than $30 \%$.

\section{Step 2. Revegetation}

If revegetation is needed, most burned areas do not require seedbed preparation if reseeding immediately following the fire. A fall dormant broadcast seeding into the ash will cover and retain seeds. The wet/dry/freeze/thaw action of the moisture during the subsequent seasons will work the seeds into the soil and break down any hydrophobic soil layers (Table 1). Frost heaving will also break down any ash crust layers that may have formed from fall rains.

The absence of a good ash layer the following fall can influence the need for seedbed preparation prior to broadcast seeding. Seedbed preparation will increase seed safe sites and enhance germination and establishment. Dragging small chains or raking the soil surface, both before and after seeding, can accomplish this. Seedbed preparation may not be feasible if the site is steep, extremely rocky, remote, and/or inaccessible; counter this by doubling or tripling the broadcast seeding rate based upon drill seeding or plowed ground. (In some cases, seeding may be impractical.)

A seed mix should contain a diversity of aggressive, quick-establishing grasses and forbs (do not include forbs if broadcast treatments of broadleaf herbicides are anticipated) that can effectively occupy available niches. A diverse plant community is likely to be weed-resistant because few resources are available to a potential invader (Carpinelli 2000).

Managers can enhance the success of revegetation by excluding livestock until vegetation is well established, usually after two growing seasons. If palatable, slow-maturing shrubs are recovering, extend excluded animals during critical growing periods.

\section{Step 3. Formulate a Burned Area Weed Management Plan}

Integrated weed management is a multi-disciplinary, ecological approach to prevent and manage invasive plants. A burned area integrated weed management plan includes the implementation of prevention and early detection strategies, effective in precluding spread and establishment into weed-free areas. Small patches respond to eradication programs and large infestations require an integrated approach in management towards the reestablishment of healthy plant communities.
Many coordinated steps must be taken outside of standard integrated weed management strategies when formulating a burned area plan. Burned area revegetation can be the first step in integrated weed management. In cases where pre-burn desired plant cover was not determined immediately following the fire, establish a burned area integrated weed management plan in areas suspected of having invasive plants and expect their rapid growth and expansion. Monitor remaining areas for new weed detection and eradication. Implement the plan immediately after the fire and anticipate a fall dormant seeding if desired vegetation cover is inadequate. A decision-making process that can assist in designing an integrated invasive plant management plan is included (Figure 1).

\section{Prevention Is Most Effective}

Preventing invasive plants from establishing into weed-free burned areas is the most effective and least costly method of weed management. This can be accomplished by limiting invasive plant seed dispersal into the burned area by:

- Using only certified invasive plantfree seed mixes when revegetation is necessary. 


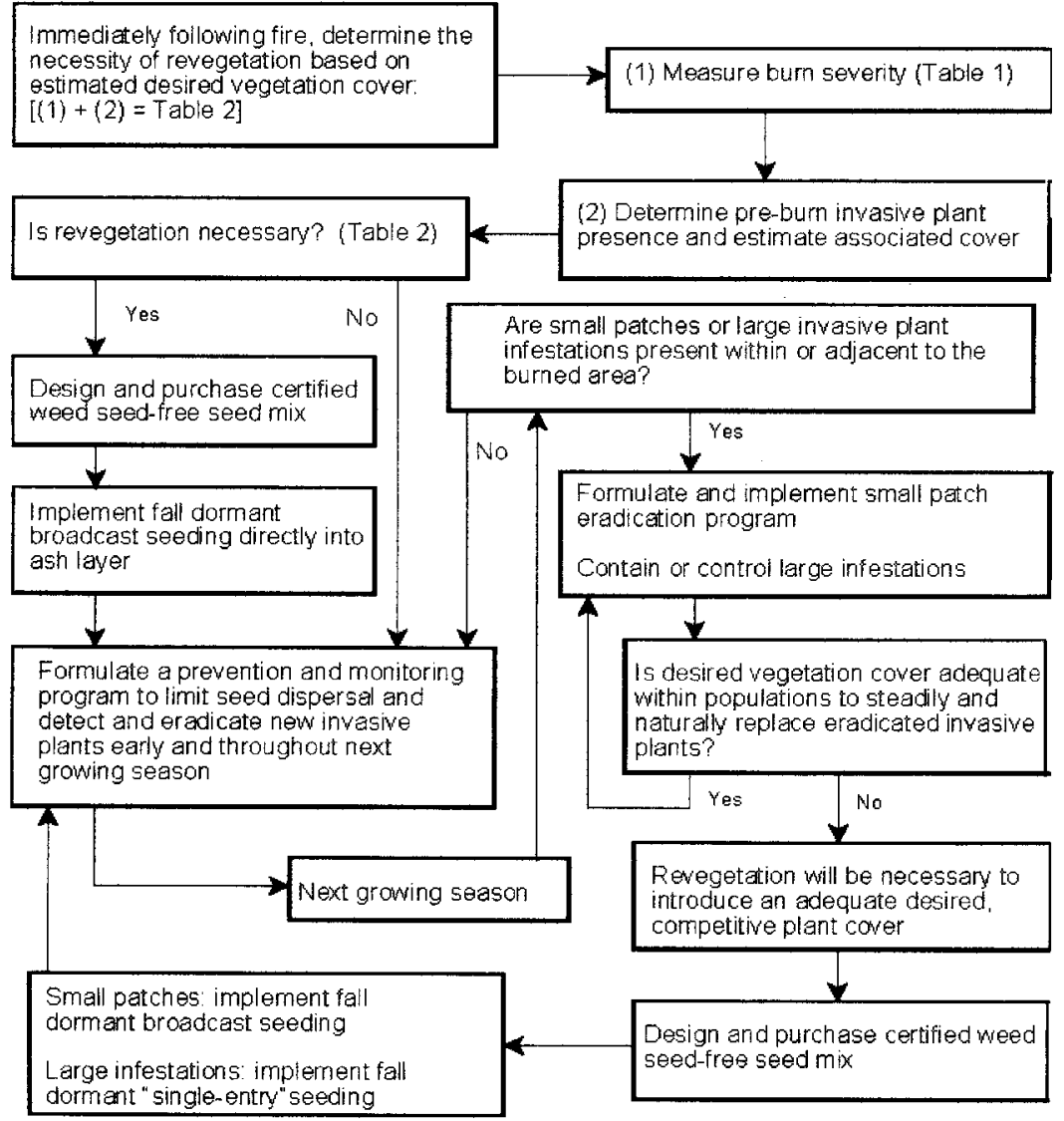

Fig. 1. Decision-making process to facilitate the formulation of a burned area integrated invasive plant management plan.

- Thoroughly cleaning the undercarriage and tires of vehicles prior to entering the burned area since invasive plant seeds are often carried along roadways

- Avoiding adjacent area invasive plant populations during the seeding period. Seeds can be transported attached to boots, clothing, and animals. Preventing movements into weed-free areas from infested areas during the seeding period can avert spread from ingestion passage and coat attachment. Livestock should be held in a drylot for at least five days to allow any viable seeds to pass, if avoidance during this period is unfeasible. (Burned area livestock exclusion is recommended to

\section{heighten vegetation recovery.)}

- Detecting weeds early and eradicating before vegetative spread and/or seed dispersal.

- Eradicating small patches and containing or controlling large infestations within or adjacent to the burned area.

\section{Early Detection}

Since invasive plants can rapidly expand after fire, a thorough early detection program is essential. Detecting and eradicating new, young invasive plants through a methodical, organized monitoring program is fundamental in preventing new infestations. Including a monitoring program within a burned area integrated weed management plan guides the identification and eradication of new plants before population development.

A monitoring program should be systematic in approach to ensure weed surveys are thorough and frequent. A program for small burned areas or smaller units within large burned areas could include the following schedule with concentrated effort along fire lines and camps, roadways, railways, and waterways, where infestations often begin:

- Spring/early summer. Methodically examine the area when young invasive plants could be hand-pulled (ensure the entire root crown is removed, especially with rhizomatous plants) or treated with an appropriate herbicide.

- Summer. Examine the area again during the early bud stage to eradicate any overlooked plants. Preventing seed production is critical to avoid spread; herbicide applications after the early flowering stage generally do not prevent seed production.

- Early fall. Examine the area again during the late flowering/early seed production stage when plants can be hand-pulled (if appropriate) or clipped. Plants should be bagged, removed from the site, and burned.

\section{Small Patch Eradiation}

Eradicating small patches adjacent to a burned area can prevent or greatly limit seed dispersal into the site. Eradication is most effective on newly established weed populations and/or those smaller than 100 square feet. Individual weeds must be removed and steadily replaced with desired, competitive vegetation (natural replacement or through revegetation) until all viable seeds are depleted from the soil. Seed dormancy and longevity in the soil contribute to long-term management required for eradication. If eradication is to succeed, reproduction must be stopped completely. Presence of weed patches directs the 
inclusion of an eradication program:

- Determine size and density of patches to prioritize management efforts (small patches with low density are most responsive to eradication)

- Annually determine changes in patch size and density to evaluate management efficacy (modify management if patch size and density are not decreasing over time)

- Flag the patches for easy relocation during the vulnerable seedling/rosette stage during spring months

- Frequent visits to:

- Implement weed removal through hand-pulling (if appropriate) or herbicide treatments

- Hand-pull or clip, bag, and burn plants prior to seed dispersal

- Implement revegetation efforts, if desired vegetation cover is inadequate within patches

\section{Managing Large Infestations}

Infestations that survived or developed as a result of fire disturbance coupled with nonexistent or inadequate weed management, will require management directed by an integrated weed management plan. The plan should prevent expansion and/or greatly limit seed dispersal, while also providing management towards the reestablishment of healthy plant communitie by shifting the competitive balance through revegetation when desired vegetation cover levels are low. There are four main management methods that, when combined as necessary, can be effective in managing large infestations: mowing, herbicides, cultural control, and in some cases, biological control.

Mowing-Proper timing of mowing is central in managing large infestations to limit seed production while also encouraging competitive vigor of desired vegetation, if present within an infestation. The most effective time to mow is during the early bud stage. Mowing each time the infestation reaches this growth stage can weaken the infestation over time by eventually depleting root reserves. This timing is especially important when mowing rhizomatous weeds since these root systems have large energy storage capacities. Frequent mowings may be necessary, but only after any regrowth has reached the early bud stage.

Infestations containing moderate to high levels of desired vegetation should be mowed short (to two inches) when the invasive plants have reached the early bud stage and the grasses have reached dormancy. This encourages unrestricted grass growth and maintenance of strong competitive vigor needed to minimize re-invasion. This also allows the grasses to produce and disperse seed for next years stand. Depending on the type of dominant grass, some weeds will bolt (or extend) above the height of these grasses. If the grasses have not reached dormancy, mowers can be set at a height directly above the seed heads of the grasses. This way, a percentage of the invasive plants are de-

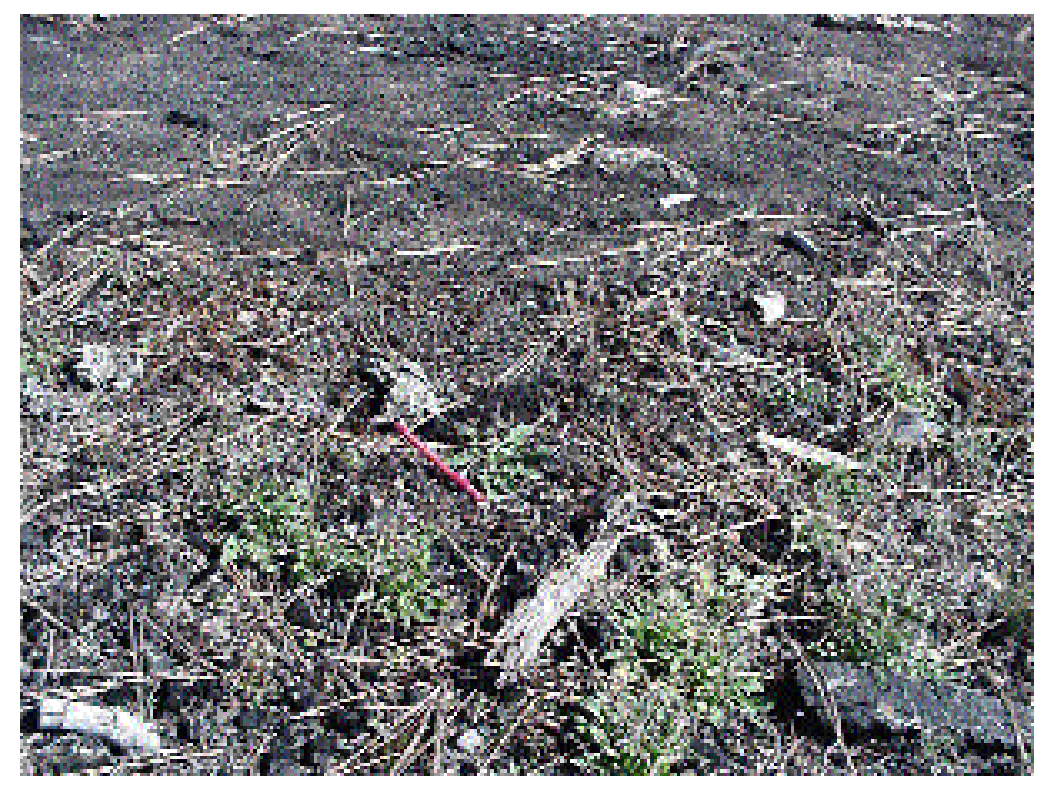

Spotted knapweed regrowth two weeks after an August 2000 fire. Desired plants are ab sent and spotted knapweed is taking early advantage of fire-produced disturbances. Photo courtesy of Bitterroot National Forest, Montana. foliated, reducing vigor and seed production, while increasing resource availability to the neighboring grasses.

Herbicide-Herbicides can provide effective management when adequate desired vegetation cover is present. The absence of such cover will allow the target weed or another weed species to become established after the residual effects of the herbicide have dissipated. To attain long-term control of an infestation with herbicides, revegetate as necessary.

The most effective time to apply a non-residual systemic herbicide to an infestation is during the seedling/rosette stage, the most vulnerable period for perennial invasive plants. Other effective times include the period between the bolt and early bud stage, and the fall regrowth stage. Herbicide treatments during these periods will ensure herbicide translocation to roots that can eradicate the plant or greatly reduce its vigor.

Timing of soil-residual herbicides is less important than herbicides with no residual activity because plants that emerge and begin to grow within the treated soil zone are still exposed to the applied herbicides through the 


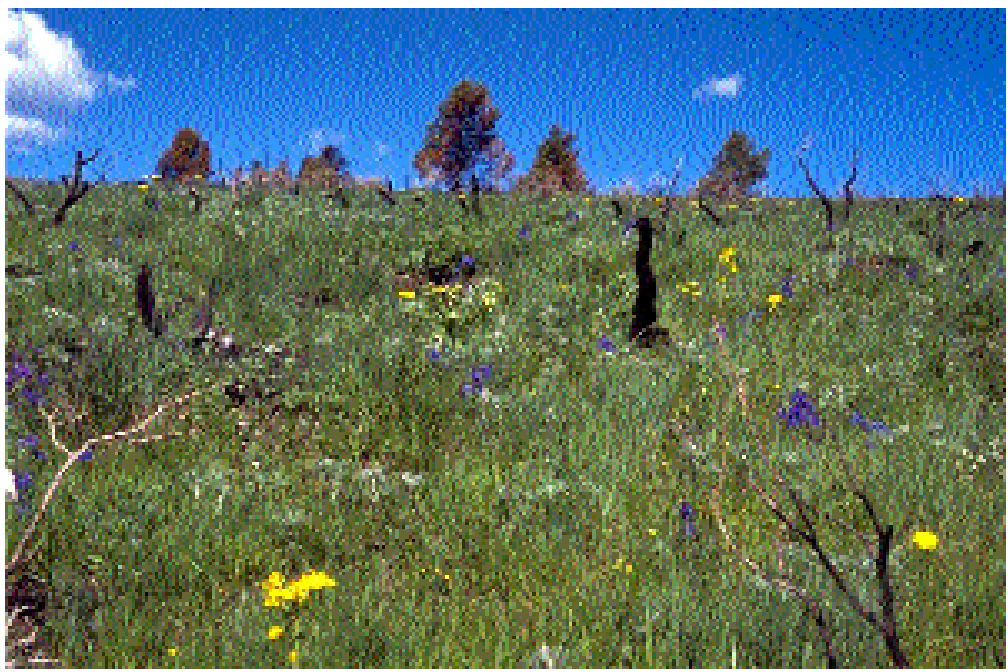

Proper implementation of a burned area weed management plan can direct recovery to wards a healthy, relatively weed-resistant plant communities. Photo courtesy of the Bureau of Land Management.

roots. The best application times for soil-residual herbicides are during the spring or fall months.

Herbicide treatments can be used to contain or control a population, depending on infestation size. A moderately sized infestation, too large to eradicate, could receive infestation-wide herbicide treatment. Revegetation, if necessary, could follow as a fall-dormant seeding.

Very large populations, too large for cost-effective control, could be contained by applying an appropriate herbicide to the borders of the infestation. This approach is designed to concentrate efforts on the advancing edge of the infestation. Containment programs for very large populations typically require a long-term commitment to herbicide application because these programs are not designed to eliminate or reduce the infestation level, only to limit its spread. In most cases, containing infestations that are too large to eradicate is cost effective because it preserves adjacent, uninfested areas and enhances the success of future large-scale control programs (Sheley et al. 1999).

Cultural-Cultural control methods promote the growth and competitive ability of desired vegetation by establishing and properly managing a healthy plant community. This can provide competition against present invasive plants and relative weed-resistance to future invaders. Cultural control methods include revegetation and grazing.

Large infestation revegetation efforts are oftentimes expensive because of the number of attempts required for success and the number of field entries needed to maximize the potential for seedling establishment (Sheley et al. 2001). However, a "single-entry" approach may provide cost-effective and reliable revegetation success. With one late-fall field entry, a residual broadleaf herbicide could be applied simultaneously as competitive grasses are seeded with a no-till drill

In one study, Sheley et al. (2001) combined eight herbicide treatments and three grass species at two spotted knapweed infested sites in southwest Montana. The best revegetation success resulted from the application of Tordon $22 \mathrm{~K}^{\circledR}$ at $1 / 2$ or one pint per acre with 'Luna' pubescent wheatgrass as the seeded species. This cost-effective and reliable "single-entry" revegetation strategy could be a major component of many sustainable weed management programs.

Cultural control through domestic sheep grazing is an effective method in managing broadleaved weed infestations while assisting the successional process towards a perennial grass climax community. When properly implemented, these benefits are accomplished through the inherent dietary preferences of domestic sheep that tend towards forbs (e.g. broadleaved weeds).The optimum time for domestic sheep grazing is during the early bud stage. This stage is most susceptible to defoliation and will have the maximum impact on an infestation. Repeated grazing during this susceptible period can weaken the infestation and over time, can reduce the ability of the infestation to compete with desired plants.

Effective control of large infestations by reducing densities through grazing is a long-term commitment. During the first few years, sheep grazing can initially increase infestation stem densities by removing apical dominance and stimulating growth of root buds in certain rhizomatous weeds such as leafy spurge. But over time, grazing can begin affecting underground reserves and eventually reduce stem densities. For instance, in Saskatchewan, Canada, summerlong continuous sheep grazing on leafy spurge had no effect on stem densities for the first three years, after which densities declined dramatically (Bowes and Thomas 1978).

Biological-Biological control methods reunite a target weed with its hostspecific natural enemies. This control method is an alternative management strategy that can be effective on some large-scale invasive plant infestations by having the ability to provide longterm, cost-effective, sustainable control. However, biological control will not eliminate or entirely prevent spread of the target weed; it aims instead at reducing the target weed density to a stable, non-damaging level based on an acceptable minimum.

Biological control can be most effective when combined with other management techniques, specifically cultural methods such as grazing and revegetation. For instance, Hansen (1993) stated that in small-scale field trials, sheep grazing and the flea beetle (a root feeder) reduced densities of leafy spurge more than sheep grazing 
or the flea beetles did alone, after three years.

\section{Conclusions}

Fire-produced disturbances directly favor colonization of new and survived invasive plants. To prevent establishment, mitigate reestablishment, and establishment and maintain healthy, weedresistant plant communities that meet land use objectives, burned and adjacent areas should be managed under a burned area invasive plant management plan. This includes revegetation if anticipated or actual desired vegetation levels are inadequate to effectively compete for available resources. A burned area plan also includes the implementation of weed preventation strategies by limiting weed seed spread and implementing an early weed detection program through systematic monitoring.
Small weed patches can be eradicated where invasive plants are removed and steadily replaced with desired vegetation until all viable seeds are depleted from the soil. Large infestation management should focus toward the reestablishment of healthy plant communities. This can be accomplished by integrating management methods such as mowing, herbicide, cultural, and/or in some cases, biological control followed by revegetation if desired vegetation cover is inadequate. Evaluate management effectiveness and modify techniques if management objectives are not being met.

Authors are Project Specialist and Associate Professor, respectively, Department of Land Resources and Environmental Sciences, Montana State University, Bozeman.

\section{References}

Bowes, G.G. and A.G. Thomas. 1978. Longevity of leafy spurge seeds in the soil following various control programs. J. Range Manage. 31:137-140.

Carpinelli, M. 2000. Designing weed-resistant plant communities by maximizing niche occupation by desirable species. Ph.D. dissertation. Montana State University, Bozeman, Mont.

Hansen, R. 1993. Effects of Aphthona flea beetles and sheep grazing in leafy spurge stands. Proc. 1993 Leafy Spurge Symposium, Silvercreek, Colo.

Lajeunesse, S., R. Sheley, R. Lym, D. Cooksey, C. Duncan, J. Lacey, N. Rees, and M. Ferrell. 1999. Leafy spurge biology, ecology and management. Extension Service Bulletin 134, Montana State University, Bozeman, Mont.

Sheley, R., S. Kedzie-Webb, and B. Maxwell. 1999. Integrated weed management on rangeland. In: Biology and Management of Noxious Rangeland Weeds (R. Sheley and J. Petroff, Eds.). pp. 57-68. Oregon State Univ. Press, Corvallis, Ore.

Sheley, R., J. Jacobs, and D. Lucas. 2001. Revegetating spotted knapweed infested rangeland in a single entry. J. Range Manage. $54: 144-151$. 